\title{
J. K. Rowling, la Covid-19 y el mundo de la edición
}

\section{J. K. Rowling, Covid-19 and the world of publishing}

\author{
José-Antonio Cordón-García; María Muñoz-Rico
}

Cordón-García, José-Antonio; Muñoz-Rico, María (2020). "J. K. Rowling, la Covid-19 y el mundo de la edición". Anuario ThinkEPI, v. 14, e14c01.

https://doi.org/10.3145/thinkepi.2020.e14c01

Publicado en IweTe/ el 21 de abril de 2020

\section{José-Antonio Cordón-García}

https://orcid.org/0000-0002-8569-9417

Universidad de Salamanca

Grupo E-Lectra

Facultad de Traducción y Documentación

Francisco de Vitoria, 6-16. 37008, Salamanca, España

jcordon@usal.es

\section{María Muñoz-Rico}

https://orcid.org/0000-0002-7333-4832

\section{Universidad de Salamanca \\ Grupo E-Lectra}

Facultad de Traducción y Documentación

Francisco de Vitoria, 6-16. 37008, Salamanca, España ricom@usal.es
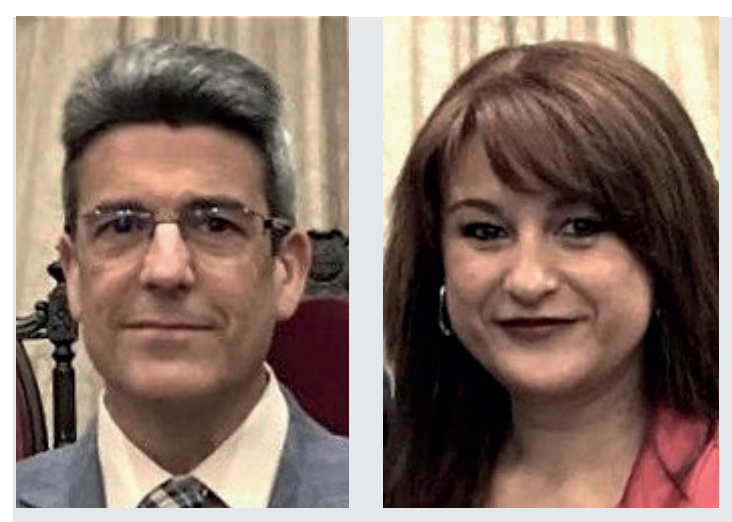

Resumen: La epidemia del coronavirus (Covid-19), desencadenada por todo el mundo, ha tenido repercusiones en todos los sectores sociales $y$, concretamente, en el mundo de la cultura en general y del libro en particular. La necesidad de adoptar medidas de confinamiento ha determinado el cierre de todos los espacios públicos relacionados con la lectura como bibliotecas, librerías y centros culturales, con graves consecuencias para el sector que ha visto como su actividad se paralizaba. Ante esta situación, han sido numerosos los actores implicados, como autores, editoriales, librerías, pero también particulares, que han llevado a cabo iniciativas para intentar paliar estos efectos, tanto para el segmento editorial, como para la población. Por una parte, se han potenciado los sistemas de adquisición online de los títulos, de compras anticipadas, de entregas flexibles, etc., y, por otra, desde el sector editorial, autores, editores y libreros han propuesto la liberación de títulos para su lectura gratuita online, o la creación de sistemas de recomendación personalizada para los lectores, entre otras muchas iniciativas. La consecuencia de todo ello ha sido un gran crecimiento del consumo de contenidos digitales, verificable sobre todo en el incremento de los préstamos en los sistemas arbitrados para ello, como E-biblio en España, y plataformas similares en otros países. Estos movimientos, aunque revisten un carácter coyuntural, han puesto de manifiesto la posibilidad de otras formas de consumo y distribución de los contenidos, poco frecuentadas por una gran parte de la población que, por necesidad, ha probado otras fórmulas de lectura que siempre quedarán bien como una alternativa a las tradicionales, bien como un complemento, bien como otro modo de apropiación y consumo que puede ser el prevalente en el futuro.

Palabras clave: Covid-19; Epidemia; Confinamiento; Editoriales; Bibliotecas; Librerías; Lectores; Libros electrónicos.

Abstract: The coronavirus epidemic (Covid-19) unleashed worldwide has had repercussions in all social sectors, and the world of culture in general and of publishing in particular have not been an exception. The need to adopt confinement measures has determined the closure of all public spaces related to reading, such as libraries, bookstores and cultural centers, with serious consequences for the sector that has seen its activity to stop. Faced with this situation, there have been numerous actors involved, such as authors, publishers, bookstores, but also individuals, who have developed a set of initiatives to try to alle- 
viate these effects, both for the editorial segment and for the population. On the one hand, the online acquisition systems, advance purchases, flexible deliveries, etc., have been strengthened. And on the other, from the publishing sector, authors, publishers and booksellers have proposed the release of titles for free online reading, or the development of personalized recommendation systems for readers, among many other initiatives. The consequence of all this has been an important growth in the consumption of digital content, verifiable above all in the increase in loans in systems such E-biblio in Spain, and similar platforms in other countries. These movements, although they are of a conjunctural nature, have revealed the possibility of other forms of consumption and distribution of content, little frequented by a large part of the population that, out of necessity, has tried other reading formulas that always look good as an alternative to traditional ones, either as a complement or as another mode of appropriation and consumption that may be the prevailing one in the future.

Keywords: Covid-19; Pandemic; Confinement; Publishing; Libraries; Bookstores; Readers; Digital books; E-books.

\section{Introducción}

En abril de 2020, con motivo de la crisis del coronavirus, J. K. Rowling lanzó una iniciativa para facilitar la lectura de las obras de la serie de Harry Potter en el domicilio, creando Harry Potter at Home, una sección dentro de la página web de Wizarding World, desde la que se podía acceder a los libros y audiolibros de la serie, de manera gratuita. Además, se podían encontrar en la página una gran cantidad de actividades relacionadas con el mundo del mago, como concursos, acertijos, artículos y vídeos de todo tipo. La liberación de las obras siguió la secuencia del orden de publicación. Durante el mes de abril de 2020 se dejó en abierto el audiolibro de Harry Potter y la piedra filosofal, que podía escucharse en inglés, español, italiano, alemán, francés y japonés, a través del sitio de Audible, vinculado con Amazon. Se trata de la versión leída por Stephen Fry, esto es, la edición británica del audiolibro. Desde las bibliotecas públicas gestionadas por OverDrive, así como desde numerosas bibliotecas escolares, los usuarios también podían tomar prestado el libro electrónico con el mismo título a través de las aplicaciones Libby - Sora, esta última dedicada en exclusiva a la lectura de los estudiantes con prestaciones adaptadas a su entorno. El proyecto fue el fruto de la colaboración de varias empresas relacionadas con el emporio de Harry Potter, de tal manera que se combinaron los recursos de las editoriales del Reino Unido y EUA, Bloomsbury y Scholastic, Pottermore Publishing, Audible, OverDrive y WizardingWorld.com.

No fue esta, sin embargo, la primera intervención de J. K. Rowling en relación con la crisis provocada por la Covid-19. El 20 de marzo de 2020 la autora anunció la creación de una licencia especial para que los profesores pudieran leer en voz alta los siete libros de la saga en sesiones virtuales y compartir las mismas en vídeo. Las condiciones de esta oferta establecían unas exigencias que, en cierto modo, intentaban compensar la liberación con la preservación de los derechos de autor, circunscribiendo su uso a los límites especificados. La oferta se restringía en el tiempo, pues su vigencia finalizaba con el año escolar, sin detallarse nada acerca del período vacacional. Por otra parte, se ajustaba a las sesiones de lectura en voz alta, que podían grabarse, pero no compartirse en las redes sociales más generalizadas y usadas por los alumnos, como YouTube, o fuera del contexto académico. Finalmente, no se permitía a los profesores modificar el texto leído, sino que habían de reproducir literalmente su contenido.

Es decir, que se trataba de una iniciativa circunscrita a la difusión de la obra, a su empleo en los ámbitos educativos, que en cierto modo es una forma de dotarla de mayor visibilidad y proyección, pero que no afectaba al núcleo de los derechos de autor, como hubiera sido la posibilidad de disponer libremente de ella por parte de cualquier usuario para su descarga gratuita.

De cualquier modo, la propuesta fue recibida con expectación por los medios, que reconocieron una modificación importante en las condiciones restrictivas que hasta entonces habían caracterizado a todos los productos generados por la factoría Rowling. La Covid-19 había logrado abrir un resquicio en la fortaleza de la propiedad intelectual y los derechos de autor contemplados desde la óptica más rígida.

Rowling y su equipo ya habían demostrado una especial habilidad para conjugar el marketing con la filantropía, la publicidad con el altruismo, o en camuflar la primera con los ropajes del segundo, por lo que esta decisión pudiera interpretarse como una formula de conveniencia para mantener la vigencia de la marca. Pero el proyecto quedaba incompleto sin la liberación total de las obras, o la posibilidad

“La Covid-19 había logrado abrir un resquicio en la fortaleza de la propiedad intelectual y los derechos de autor contemplados desde la óptica más rígida" 
de contar con una conexión a la Red. La creación, poco después, del sitio de Harry Potter at Home, venía a completar ese primer anuncio, afectando, ahora sí, a las condiciones de acceso y lectura de las obras.

Estas iniciativas muestran los reflejos de Rowling, y de sus empresas asociadas, para reforzar su vertiente social, que ya ha mostrado en numerosas ocasiones a través de subastas, donaciones o colaboraciones con campañas solidarias de todo tipo. Independientemente del efecto publicitario de las mismas, traducido en cientos de miles de réplicas en páginas web y redes sociales, muestran la vigencia de un fenómeno que alcanza un eco multitudinario para todas aquellas acciones que se emprenden desde el mismo. En este caso lo ha hecho sumándose a los proyectos de numerosas editoriales que han liberado algunos de sus contenidos para atender a una demanda inusual, y limitada en el tiempo, a la que se han unido casi todos los actores de la cadena del libro, no siempre sin polémica, como el lanzamiento de la National Emergency Library por parte de Internet Archive en marzo de 2020, con objeto de facilitar el préstamo digital de los cientos de miles de obras que tiene entre sus fondos.

https://archive.org/details/nationalemergencylibrary

Fue la respuesta de la institución a la emergencia mundial creada por la pandemia del coronavirus, con las bibliotecas universitarias, escolares y públicas de todo el mundo cerradas. Bien recibida desde algunos sectores, fue rotundamente rechazada por la Association of American Publishers, por Author's Guild, la asociación profesional de escritores más antigua y prestigiosa de los Estados Unidos, y por la Society of Authors de Londres. Estas instituciones argumentaban que se estaba cometiendo una ilegalidad por cuanto se estaba disponiendo de derechos sobre obras, sin permiso de sus autores y/o editores. Muchos autores se pronunciaron en el mismo sentido cuestionando los beneficios de una acción cuyos principales perjudicados eran precisamente aquellos a los que se pretendía defender. Internet Archive ya contaba con una amplia colección de obras, gestionadas para el préstamo gracias a la creación del Open Library Project que, amparado en la doctrina del Controlled Digital Lending $(C D L)$, permitía el préstamo de sus obras con limitaciones, y que, en su momento, ya fue considerado como una violación masiva de los derechos de autor por parte de escritores y editores (Anderson, 2019; Association of American Publishers, 2019). El escritor e investigador David Newhoff, ya había acusado al sitio de utilizar la pandemia para justificar el saqueo (Newhoff, 2020). Open Library Project restringía el préstamo a un usuario por copia, pero a partir del 24 de marzo de 2020 se suprimió esta limitación, debido al estado de emergencia, y se permitió el préstamo ilimitado. Internet Archive justificaba su actitud en el hecho de que cientos de bibliotecas, con libros pagados por los ciudadanos con sus impuestos, habían quedado inaccesibles para la población, que no podía hacer uso de sus colecciones, como les correspondía por derecho (Strauss, 2020). El problema, como indicaba Hasbrouk (2020), miembro de la National Writers Union, es que los usos de la plataforma sobrepasaban al mero préstamo digital de libros, extendiéndose a la redistribución de copias no autorizadas de imágenes, al audio generado a partir de ellas, y a otros usos que se concretan en cinco tipos de prácticas de los que solo uno coincide con los reconocidos por el sitio:

- Descargas a través de OpenLibrary.org de libros electrónicos reunidos a partir de imágenes de página. Este modo de distribución de copias no autorizadas de imágenes escaneadas de libros impresos corresponde, en su mayoría, a lo que se ha descrito como "Préstamo digital controlado" (CDL).

- Audiolibros generados a partir de imágenes de páginas escaneadas.

- Visualización de imágenes de página en OpenLibrary.org.

- Visualización de imágenes de página en Archive.org.

- API para descargas automáticas de imágenes de página.

Independientemente de ello se trata de una interesante polémica sobre el derecho de acceso a la información y los derechos de propiedad intelectual de autores y editores. 


\section{El mundo del libro y la Covid-19}

Son muchas las propuestas, académicas, profesionales y de ocio, que han sido generadas desde las editoriales, desde los grandes grupos a las empresas más pequeñas'.

En España el Grupo Planeta, por ejemplo, puso a disposición de los lectores una selección de títulos para su descarga de manera gratuita, entre las que se encontraban:

- La sombra del viento, de Carlos Ruiz Zafón;

- El código Da Vinci, de Dan Brown;

- El tiempo entre costuras, de María Dueñas;

- Los hombres que no amaban a las mujeres, de Stieg Larsson;

- Las crónicas de Narnia: El león, la bruja y el armario, de C. S. Lewis.

Además, creó el espacio \#KeepReadingEnCasa, un lugar en el que desplegaron diariamente una agenda de actividades con autores como Dolores Redondo, Almudena Grandes, Santiago Posteguillo o Elvira Lindo. En el mismo espacio se diseñó una programación de actividades para los niños como cuentacuentos, talleres varios o concursos de cuentos bajo el título Superhéroes contra Coronavirus.

Nubico, el sistema de suscripción de lectura digital del Grupo Planeta y Telefónica, anunciaron igualmente que durante 2 semanas se podría acceder gratis a su catálogo de manera ilimitada. Anagrama fue otra de las editoriales que liberó algunas de sus obras con la puesta a disposición de los lectores de

- Años felices, de Gonzalo Torné;

- Las cosas que perdimos en el fuego, de Mariana Enríquez;

- Un buen detective no se casa jamás, de Marta Sanz;

- Fiesta en la madriguera, de Juan Pablo Villalobos;

- Mis documentos, de Alejandro Zambra.

Roca Editorial puso inicialmente 17 libros a cero euros en las principales plataformas de libros electrónicos y el grupo Penguin Random House llevó a cabo un buen número de actividades sin salir de casa relacionadas con la lectura y los libros.

Errata naturae se incorporó también a las iniciativas de gratuidad con una de las propuestas más originales. En el comunicado planteando la misma, deja claras sus posiciones de partida y los propósitos de esta:

"Queridos lectores y lectoras de Errata naturae,

Desde hace una semana, todo el equipo de nuestra editorial está trabajando desde su casa y limitando al máximo sus contactos sociales, según propuso en su momento la Consejería de Salud y exige ahora el Ministerio de Sanidad. En la medida de lo posible, tratamos de continuar con nuestras labores, pero también nos gustaría ofreceros, como fieles seguidores de los libros de la editorial, nuestro apoyo, y demostraros nuestro cariño en una situación que para todos está siendo muy difícil.

Creemos que las situaciones excepcionales requieren decisiones excepcionales, y que en los momentos críticos debemos olvidar tanto el business as usual como el thinking as usual, y apostar más que nunca por las redes colaborativas, el apoyo mutuo, la empatía, la confianza, la intuición y la improvisación.

Por todo ello, hemos decidido liberar y distribuir gratuitamente una veintena de los títulos de nuestro catálogo, de modo que, a pesar de las restricciones y la necesaria cuarentena, todos sigamos leyendo buenos libros y teniendo la oportunidad de hacernos mejores con cada página durante los largos días que nos esperan.

Todos los libros que podrás descargarte de forma gratuita aquí abajo son, por distintas razones, prácticamente inencontrables en las librerías. Tengamos todos en cuenta que ésta es una situación absolutamente anómala. Sin embargo, no olvides que, siempre que sea posible, los libros deben comprarse a través de ese librero que lleva tantos años descubriéndote nuevos títulos o a través de ese editor en cuyas elecciones has aprendido a confiar.

La propuesta de esta editorial se aleja de las precedentes en la medida en que la selección responde a unos criterios originales que ejercen de recomendadores indirectos. Los epígrafes y las obras de cada uno de ellos serían:

a) Para los que busquen estos días historias distópicas, reales o imaginarias:

- Entre los archivos del distrito, de Kenneth Bernard;

- Sofia Petrovna: Una ciudadana ejemplar, de Lidia Chuskóvskaia;

- La iniciación de un hombre: 1917, de John Dos Passos;

- Sueños, de Franz Kafka.

b) Para los que quieran pensar críticamente incluso en una situación crítica:

- Pensar desde la izquierda: mapa del pensamiento crítico para un tiempo de crisis, de Giorgio Agamben et al.; 
- Contribución a la guerra en curso, de Gilles Deleuze y Tiqqun²;

- Las cazas del hombre: el ser humano como presa de la Grecia de Aristóteles a la Italia de Berlusconi, de Gregoire Chamayou;

- A través de los muros: cómo el ejercito israelí se apropió de la teoría crítica postmoderna y reinventó la guerra urbana, de Eyal Weizman.

c) Para los que, al contrario, necesiten reírse un poco:

- El bibliómano ignorante. Seguido de Si busca la vida buena, icompre uno de nuestros estilos filosóficos!, de Luciano de Samósata;

- El compañero de piso de mierda: guía de supervivencia para compartir casa, con textos de Angelo Fiori e ilustraciones de Dario Campagna.

d) Para los que quieran olvidarse unas horas de Netflix sin olvidarse del cine ni de las series:

- Mutaciones del cine contemporáneo, de Jonathan Rosenbaum y Adrian Martin (coords.);

- Los Soprano forever: antimanual de una serie de culto, de varios autores.

e) Para los que tengan peques y necesiten ideas:

- El genio maligno del señor Descartes (basado en las Meditaciones Metafísicas), textos de Jean Paul Mongin e ilustraciones de François Shwoebel;

- El filósofo-perro frente al sabio Platón;

- Un día en la vida del profesor Kant.

Con cada uno de ellos se ofrecen sendas unidades didácticas con propuestas de lectura, que incluyen actividades para el ámbito familiar, escolar y para las instituciones de fomento de la lectura, así como pasatiempos.

f) Para los que no tengan peques ni ganas de tenerlos: El niño criminal, de Jean Genet.

g) Para los buenos lectores de la mejor novela negra (y sus periferias):

- Interrogatorios, de Dashiell Hammett;

- Guía de la novela negra, de Héctor Malverde;

- Juicio contra una prostituta, de Demóstenes.

h) Para los que saben que, en las situaciones difíciles, lo mejor es ir por partes: El destripador, de Robert Desnos.

La editorial Alba, también añadió a su catálogo una serie de libros gratuitos:

- En vísperas, de Iván Turguénev;

- Huracán en Jamaica, de Richard Hugues;

- Mi enemigo mortal, de Willa Cather;

- El misterio de Notting Hill, de Charles Warren Adams;

- Nuestro corazón, de Guy de Maupassant;

- Amor y amistad, de Jane Austen;

- El Eco, de Henry James;

- Lo más selecto, de Henry James.

Estuvieron disponibles entre el 19 y el 26 de marzo, aunque después volvieron a sus precios normales. Y Blackie Books puso en marcha la iniciativa Casa Blackie compartiendo en su perfil de Instagram el pdf de Instrumental, el libro de memorias del pianista británico James Rhodes, ahora residente en España, en el que cuenta los problemas de abusos sexuales que sufrió durante su infancia.

También son varios los autores que han ofrecido algunas de sus obras en descarga gratuita, como Rosa Montero con su novela La vida desnuda; Juan Gómez Jurado con El paciente; Blas Ruiz Grau con todos su ebooks y muchos otros. Los autores se han implicado de muchas otras maneras en este movimiento, como a través de sistemas de recomendación, amparados por la autoridad que les confiere su posición como referentes culturales y/o mediáticos. Así la Escuela de Escritores puso en marcha la campaña Te receto un libro, mediante la cual conocidos autores mantuvieron encuentros virtuales con los supuestos "pacientes" que habían pedido una cita. La consulta se resolvía con una recomendación según los síntomas mostrados. No se trata de una idea original, pues ya había sido puesta en marcha en la Feria del libro de Madrid, pero su éxito sobrepasó todas las previsiones. La presentación del servicio es muy elocuente y persuasiva:

“¿Te imaginas ir al médico y que te expida una receta literaria? Un libro que te acompañe durante estos días de aislamiento, que te ayude a superar la nostalgia, la ansiedad o el mal de amores. Porque un libro no solo puede ser un buen acompañante para los buenos momentos: hay libros 
que nos curan el alma (y a veces también el cuerpo). Solo tenemos que encontrar el más indicado para nuestra 'dolencia', el que mejor se adapta a nuestras necesidades y gustos, y aprender a administrar nuestras lecturas.

Abra la boca, diga 'aaaa' y cuénteme, cuénteme... ¿Qué libros le gustan? ¿Es usted más de novela histórica o de poesía social? ¿Le apasiona el álbum ilustrado? ¿El ensayo, quizás? ¿No tendrá usted el corazón roto? ¿Tal vez sufre de estrés? ¿O quizás necesita más emociones en su vida? Venga, que ya queda poco para acabar la consulta. Mire fijamente este punto y siga mi dedo con la mirada. ¡Estupendo! Pues ya hemos terminado. Le voy a recetar unos cuantos libros que seguro le gustarán y le ayudarán a sentirse mucho, mucho mejor...

Los librólogos de Escuela de Escritores se encargarán de encontrar el psicofármaco que necesitas durante los días que dure la cuarentena. De lunes a viernes en horario de 17:00 h a 19:00 h (hora peninsular de Madrid, España), nuestros facultativos te escucharán atentamente y, una vez valorado el "caso", te darán su diagnóstico en forma de receta literaria con la seguridad de que su lectura mitigará tus "dolencias" sin efectos secundarios. Además, contamos con un equipo de expertos en Librología Pediátrica para atender también las necesidades de niños y adolescentes. https://escueladeescritores.com/te-receto-un-libro

El calendario de citas incluía autores de múltiples géneros y estilos para que los lectores o interesados se inscribieran con aquel que mejor se adaptara a sus querencias. El censo de autores incluía a: Manuel Vilas, Marcelo Luján, Ana Merino, Ignacio Ferrando, Juan Cruz, Rubén Abella, Luis Luna, Mónica Rodríguez (bibliopediatría), Leila Guerriero, Fernando Clemot, José Ovejero, Inés Mendoza, Lara López, Benjamín Prado, Fernando Navarro, Inés Mendoza, Javier Sagarna, Chiki Frabegat, Rosa Montero, Elvira Navarro, Dario Adanti, Bruno Galindo, Luis Luna, Javier Fonseca y Marta Sanz, que fue la primera en abrir la campaña, el martes 7 de abril de 2020. Las sesiones contaban con una duración de 2 horas, entre las 17 y las 19 horas, y cada uno de los "pacientes" podía estar 10 minutos con el autor, siempre que hubiera horas disponibles, pues la demanda, como se ha indicado, pronto sobrepasó las expectativas, y las reservas agotaban pronto la disponibilidad horaria.

El éxito de estas iniciativas es congruente con las tendencias observadas en las prácticas de lectura a través del tiempo. Si observamos la evolución de las razones aducidas por los lectores para la elección del último libro leído, recogidas en el informe de Hábitos de Compra y Lectura de Libros, publicado por la Federación de Gremios de Editores y el Ministerio de Cultura, veremos que las recomendaciones ocupan un lugar muy importante

Tabla 1. Evolución de las motivaciones para la selección de libros leídos. Fuente: Informes de hábitos de lectura y compra de libros 2000-2012 (\%).

\begin{tabular}{|l|c|c|c|c|c|c|c|c|c|c|c|}
\hline Año & $\mathbf{2 0 0 0}$ & $\mathbf{2 0 0 1}$ & $\mathbf{2 0 0 2}$ & $\mathbf{2 0 0 3}$ & $\mathbf{2 0 0 4}$ & $\mathbf{2 0 0 7}$ & $\mathbf{2 0 0 8}$ & $\mathbf{2 0 0 9}$ & $\mathbf{2 0 1 0}$ & $\mathbf{2 0 1 1}$ & $\mathbf{2 0 1 2}$ \\
\hline Temática & 41,5 & 79 & 77,9 & 90,4 & 93,3 & 89,3 & 91 & 91,9 & 78,7 & 75,4 & 74,6 \\
\hline Título & 11,8 & 48 & 47,1 & 48,6 & 44,1 & 50,6 & 48,6 & 47,8 & 17,3 & 14,6 & 14,8 \\
\hline Recomendaciones & 15 & 37 & 40,9 & 64,7 & 72,1 & 74,2 & 76,7 & 76 & 42,4 & 46,5 & 44,1 \\
\hline Autor & 23,3 & 26 & 39,6 & 55,2 & 56,9 & 60 & 60,1 & 58,7 & 54,4 & 48,6 & 53,2 \\
\hline Precio & 5,5 & 23 & 20,9 & 41,9 & 43,9 & 46 & 46,5 & 49,3 & 18,2 & 15,7 & 18,3 \\
\hline Cubierta & ---- & 28 & 15,5 & 25,4 & 31,6 & 35,4 & 33,4 & 34,9 & 9,5 & 8,6 & 8,8 \\
\hline Publicidad & 1,4 & 17 & 15,6 & 21,8 & 21,5 & 28,1 & 26,7 & 29,1 & ----- & ----- & ----- \\
\hline Criticas & 2,5 & 14 & 12,2 & 27,1 & 30,9 & 34,9 & 32,9 & 34,2 & 23,9 & 26,5 & 28,9 \\
\hline Editorial & 1,3 & 8 & 7,8 & 6,8 & 6,2 & 13,1 & 9,8 & 9,1 & 2 & 1,5 & 2,7 \\
\hline
\end{tabular}

En los años 2017-2019³ se confirman los supuestos y la jerarquía de estos. De tal manera que la triada tema, autor, recomendaciones constituye el eje sobre el que ha de articularse toda estrategia editorial. Pero sobre todo sitúan a las recomendaciones en un lugar estratégico para que un libro adquiera proyección y visibilidad. De hecho, cuando se pregunta cuáles son los criterios para buscar información sobre un nuevo libro que se quiere leer, la respuesta es bastante ilustrativa (figura 2).

Por lo tanto, no es extraño que la campaña de la Escuela de Escritores haya alcanzado un impacto inesperado. La recomendación se está convirtiendo en una de las claves de la comunicación cultural, y una iniciativa que redunde en ella, además con personas de referencia, incide en uno de los aspectos más valorados por los lectores (Cordón-García; Gómez-Díaz, 2019)

Pero ha sido en el ámbito de la literatura infantil y juvenil donde las iniciativas se han multiplicado, con objeto de dotar a este sector de edad, y a los padres, de instrumentos para ocupar el tiempo (hay 
que tener en cuenta que se trata de una población habituada a unos horarios cautivos entre las clases y los juegos), sin el inmovilismo y las limitaciones impuestas por la crisis. La coincidencia del período de confinamiento con la celebración del Día Internacional de Libro Infantil y Juvenil (fecha en la que se conmemora el nacimiento de Hans Christian Andersen), resultó propicia para la multiplicación de propuestas dirigidas a este sector de la población.

Editoriales como SM, Maeva Young, el grupo Penguin Random House, etc., llevaron a cabo desde encuentros virtuales con autores hasta cuentacuentos, en canales de YouTube, y manualidades varias que se van renovando regularmente:

- Libros del zorro rojo, comparte algunas actividades del libro Manos a la tierra, de Kirsten Bradley;

- desde la cuenta @EscobarLicense, de los herederos del creador de Zipi y Zape, se regala un álbum descargable de esta pareja, que además ayuda a practicar el inglés y el francés;

- otra iniciativa, coloreable, es la del dibujante de cómic José Fonollosa, que desde la web de Grafito Editorial ofrece descargar un cuaderno de más de 20 ilustraciones de Vampi y sus amigos;

- el dibujante Pepo Pérez ofrece la posibilidad de descargar un recortable de la figura del personaje de Titán, protagonista de la serie El vecino (Astiberri), que publica con Santiago García, y que Netflix trasladó a la televisión como saga.

En el terreno de los creadores de cómics han surgido también numerosas iniciativas como:

- El ilustrador Pau Valls que regala en Twitter historietas de su serie Náufragos, publicada semanalmente en el Diario de Levante.

- El Torres (Juan Antonio Torres García), autor de El fantasma de Gaudí, que fue Premio del Salón del Cómic de Barcelona 2016, ha puesto en libre acceso para la descarga Cuentos del bosque de los suicidas (con Fran Galán), El velo (con Gabriel Hernández), Apocalypse girl (con Ramiro Borrallo) Las brujas de Westwood y Tambores (ambas con Abel García). También compartió desde el mismo hilo de Twitter el catálogo de Cómics Karras hasta el 30 de marzo.

- Santiago García junto con el dibujante Javier Olivares (con quien ganó el Premio a la mejor obra española en el Salón Internacional del Cómic de Barcelona 2015, con Las meninas), en su blog Mandorla ofrece una variedad de páginas de El vecino (con Pepo Pérez), La cólera y la gripe (con Javier Olivares), o García y Antonia (con Luis Bustos).

El sello independiente AfterCOMIC, bajo el denominador común de Yomequedoencasa, ha puesto a disposición de sus lectores varios contenidos descargables, desde una novela de terror para adultos, hasta un cómic pensado para los niños, Little Renna y el desafío de la gorgona, y una colección de ilustraciones para colorear para los más pequeños.

\section{El problema de las librerías}

La European and International Booksellers Federation (EIBF) hizo un llamamiento a los gobiernos de todo el mundo para proteger a las librerías en estos momentos de crisis, apelando a la función de estas desde el punto de vista económico, cultural y educativo.

https://bit.ly/2Vj40zp

Un estudio de la Harvard Business School (Raffaelli, 2020) mantenía que las librerías independientes disfrutaban de tres ventajas distintas:

- fomentaban un sentido de comunidad entre las empresas y los consumidores;

- sus productos estaban adaptados específicamente para su clientela; 
- eran lugares donde la gente podía reunirse físicamente, interactuar con los empleados, recibir un trato personalizado, reconocerse en muchos de los otros visitantes, etc.

Un contexto especialmente aprovechable por los editores que buscaban sinergias para escapar de las presiones y abusos de los gigantes de la producción y distribución online. Y una tabla de salvación para las editoriales independientes que encontraban en esta correlación estructural (Bourdieu, 2018) el fundamento y la garantía que le proporcionaba visibilidad a muchos de sus lanzamientos. Pero el confinamiento rompió esta suerte de cordón umbilical beneficiando sobre todo a los mayoristas online y principalmente a Amazon, contra el que ya se habían manifestado, desde antes de la epidemia muchos de los actores de la cadena del libro.

En 2019 de publicó Contra Amazon, en la editorial Galaxia Gutenberg, en el que se hacía una encendida defensa de las librerías independientes, del placer del descubrimiento, de la lectura sosegada, y en definitiva de un mundo alejado del monopolio y la avidez de los grandes emporios oligopolísticos (Carrión, 2019). Amazon forma parte del denominado grupo GAFA (Google, Apple, Facebook y Amazon), cuyos miembros han sido señalados como los grandes sistemas de servicios de producción y distribución que dominan el mercado en la actualidad, con una fuerte tendencia al desarrollo de nuevas formas de editorialización centradas en fagocitar a todos los elementos que puedan entorpecer sus objetivos monopolísticos (Ertzscheid, 2017). La estrategia de precios desarrollada por el gigante constituye una barrera insuperable para sus competidores (Reimers; Waldfogel, 2017). El modelo de venta mayorista, frente al modelo de agencia, elegido por ejemplo por Apple, había reforzado su carácter preponderante en el sector, influyendo en la articulación del sistema global de la comercialización de libros en todo el mundo (Wirl, 2018). El dominio de Amazon se fundamentaba no solo en una logística impecable, que lleva cualquier producto a domicilio en un tiempo récord sino, en el caso del libro, en otros servicios complementarios como la creación de una red social de lecturas, primero de manera autónoma, después con la compra de Goodreads (Maity; Panigrahi; Mukherjee, 2017), y con el desarrollo de algoritmos de recomendación que han potenciado esta función dentro de la plataforma (Hou; Liu; Liu, 2018), incorporando el análisis de sentimientos en los mismos (Strujan et al., 2018; Almjawel et al., 2019).

Si en una situación normal las ventajas competitivas de la empresa eran un muro inexpugnable, en un momento en el que la comercialización online adquiere el protagonismo, la falta de adaptación a la misma constituyó un mecanismo de selección comercial demoledor.

Las librerías, como señala Shephard (2020), no podían activar lo que mejor saben hacer: reunir a las personas. El problema para muchas de estas, y principalmente las independientes fue que no habían dado el salto a la venta minorista en línea. Esta situación se intentó paliar con iniciativas como Bookshop.org, en EUA, un nuevo sitio web que conectaba las librerías independientes con los consumidores. En España, la Confederación Española de Gremios y Asociaciones de Libreros (Cegal), que reúne a 1400 librerías, estimaba en 200 millones de euros las pérdidas previstas por el paro del negocio presencial,

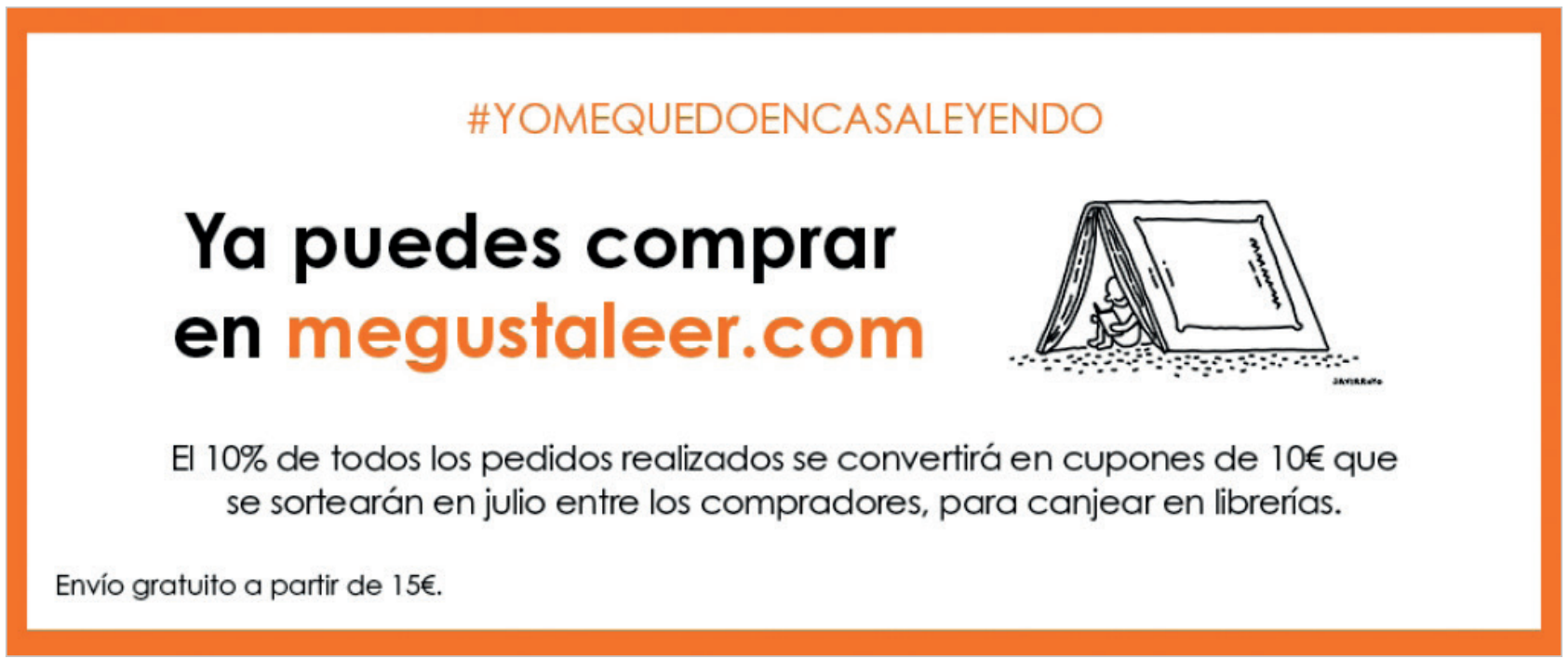

Figura 3. Campaña de apoyo a las librerías de Penguin Ramdom House.

Fuente: $h$ ttps://bit.ly/2KhYxCL 
dado que solo una cuarta parte de ellas integran internet como canal de venta. De ahí que solicitaran al Ministerio de Cultura la posibilidad de que las librerías pudieran ser puntos de recogida de pedidos de libros que se hubieran hecho a través de la Red, sin que esto supusiera apertura al público. Sin embargo, la respuesta por parte del Ministerio aún no se concretado en medidas específicas para el mundo del libro. Únicamente se propuso, por parte de la ministra de Hacienda, la posibilidad de rebajar el IVA del libro electrónico y la prensa digital del 21 al 4\%. Esta propuesta se aprobó en el consejo de ministros del 21 de abril de 2020. Esto equipara a los libros digitales con los impresos en el disfrute del IVA superreducido del 4\%, algo que se esperaba desde el año 2016, cuando la Comisión Europea aprobó en diciembre de ese año una reforma para que los estados miembros pudieran realizar esta reducción. La diferencia de precios carecía de sentido desde el momento en que, como declaró el comisario de Asuntos Económicos de la Comisión "Sea papel o digital, un libro es un libro y un periódico es un periódico". Con esta medida se satisface una de las reivindicaciones del sector del libro, que venía reclamándola desde hace años.

Las iniciativas privadas, en cambio, han surgido desde el primer momento, aunque con un carácter muy distinto según el origen de las propuestas. El grupo Penguin Random House lanzó una iniciativa aparentemente respetuosa con los intereses de las librerías, pero como señala Bernat Ruiz, no fue más que "interés disfrazado de altruismo" (Ruiz, 2020).

La trampa, como indica Ruiz, es que un librero se lleva alrededor del $30 \%$ del PVP de cada libro vendido. Si Penguin Random House destina el $10 \%$ de cada venta directa en su tienda a un fondo para un sorteo para repartir cupones en el mes de julio, se está quedando con un $20 \%$ del PVP del que habitualmente no dispone.

Una interesante iniciativa fue la que pusieron en marcha más de 40 editores independientes en Cataluña, que bajo el lema Desconfinemos los libros, animaban a los lectores a la adquisición de obras a través de plataformas online como Libelista, que une a una extensa red de librerías independientes y garantiza que el $100 \%$ de lo que el usuario paga revierta en las empresas.

La editorial Nórdica lanzo una iniciativa, a la que pronto se unieron otras editoriales como Barrett y Dos Bigotes, Bunker Books y Distrito 93, consistente en destinar un $35 \%$ de todas las compras hechas en su página web a la librería de España que el comprador decida. De tal manera que al adquirir el libro el cliente debe especificar a qué punto de venta quiere que vaya destinado ese porcentaje.

Se trata de una propuesta

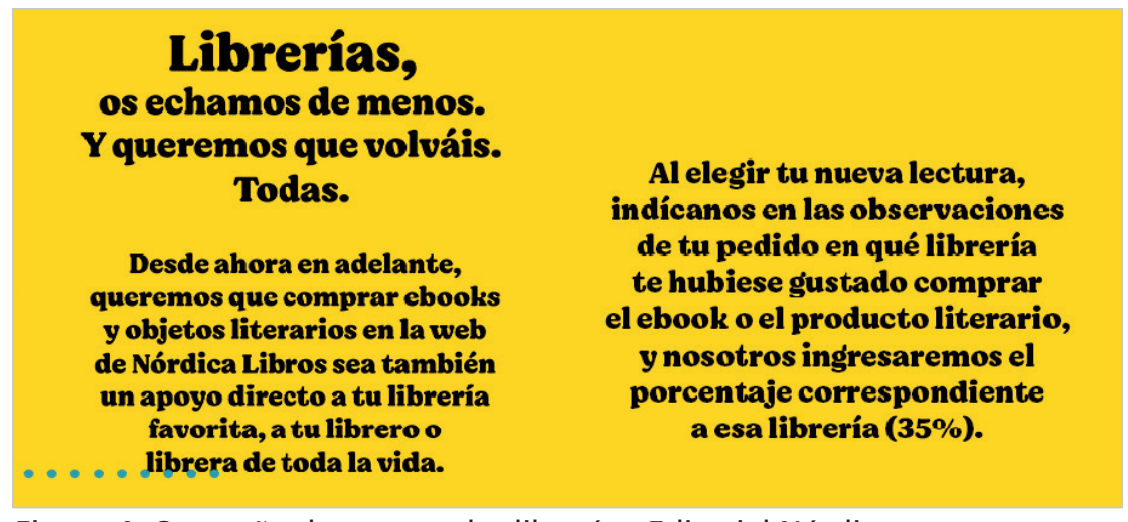

Figura 4. Campaña de apoyo a las librerías. Editorial Nórdica. Fuente: https://www.nordicalibros.com

\section{parecida a la que, en Italia,}

lanzó la editorial Eris, bajo la consigna de Adotta una libreria, gracias a la cual los lectores repercuten en una librería independiente, que cambia a diario, un porcentaje de las compras hechas en la web del establecimiento.

https://bit.ly/3cvFaSG

En Francia se llevaron a cabo múltiples acciones por parte de los diferentes actores, agrupadas todas en el sitio web Je soutiens ma librairie.

https://www.jesoutiensmalibrairie.com 
Una de las acciones recogidas, bajo la denominación de Cagnotes, consistía en comprar libros en cualquier librería, para recogerlos una vez se hubiera declarado el fin del confinamiento. Lo singular de la acción es que, en su descripción, además de apelar a los motivos de la misma, se alude a Amazon de manera vaga pero significativa, aduciendo el beneficio de que sea el librero el que entregue el libro en lugar de la multinacional.

Otros apoyos provienen de entornos externos al mundo empresarial, como es el caso de la campaña Sigue Leyendo, una iniciativa en la que posibilita la adquisición de unos Vales para leer, por un valor de entre 5 y 50 euros, que el usuario destina a la librería elegida. Estos bonos se convierten en libros una vez que la librería abra. Se trata por lo tanto de una suerte de inversión anticipada sobre compras futuras.

https://paraseguirleyendo.com

Son muchos los ejemplos que se podían incluir en este terreno, en el que creadores, editoriales y plataformas de diverso tipo han respondido de una manera unánime al llamamiento de ayudar cada uno desde su ámbito.

\section{Entre la necesidad, el marketing y la filantropía: las motivaciones y los hechos}

Según la constante de Boltzmann, en un sistema cerrado la entropía prevalece y el caos se impone al orden. $Y$ esto es lo que parece que ha estado ocurriendo en el ámbito de las industrias culturales en el contexto de crisis desencadenada por la Covid-19. A pesar de este cúmulo de iniciativas y campañas, de la falta de iniciativas oficiales y del voluntarismo espontáneo vinculado con estas carencias, se pueden establecer algunos factores estructurales subyacentes en las diversas actuaciones.

En primer lugar, hay razones de carácter económico. La mercantilización de la cultura, que está en el trasfondo del fenómeno de la lectura contemporánea, ha supuesto que una crisis que afecta a los fundamentos del mercado, por cuanto el confinamiento supuso la inmovilización del comercio, haya colapsado toda la cadena de valor del libro tradicional. Autores, editores, bibliotecas y librerías se han visto en una situación de parálisis de la que únicamente han podido salir aquellos que mejor posicionados estaban en el entorno digital. Los beneficiados de toda esta trama han sido, sin ninguna duda, y a tenor de los datos que van apareciendo, las plataformas digitales, las de suscripción y los grandes grupos que publican obras comerciales de gran consumo ${ }^{4}$. También las bibliotecas, en su vertiente virtual, por cuanto el préstamo de libros electrónicos, que comenzaba a despegar después de años de atonía, ha alcanzado cotas desconocidas 5 . No quiere decir esto que las ventas digitales compensen las pérdidas previstas para los libros impresos, pero en algunos casos sirven para compensarlas, siempre estimando el peso relativo que todavía guarda la edición digital respecto a la de papel. Ello no es óbice para que el periodo de cierre de librerías constituya una debacle para estas, y para los editores, cuyo mayor porcentaje de ventas se cifra en el comercio minorista. También en los autores repercute económicamente la recesión, pues no solo dejan de percibir los derechos de venta, sino también los indirectos inherentes a las presentaciones de obras, que se han visto paralizadas por el cierre de librerías y centros culturales y por la congelación de los nuevos lanzamientos decidida por los editores, a la espera de la reanudación de las actividades comerciales. La cancelación de celebraciones como el Día del Libro, o de ferias como las de Madrid, Bolonia, Guadalajara, etc., también ha supuesto un lucro cesante significativo, en la medida en que algunos comercios llegan a obtener un elevado porcentaje de sus rendimientos totales en estos eventos. Se habla de "libros fantasmas" para referirse a los que han salido en estas fechas de reclusión, pero sin embargo no han tenido salida en las librerías, cerradas, ni llegado a los lectores, faltos de la visibilidad requerida. Sin embargo las consecuencias económicas de la crisis no afectan a todos los sectores por igual, son las editoriales independientes, cuyo negocio depende en gran medi- 
da de los resultados casi inmediatos de ventas, las pequeñas librerías, que salvan sus cuentas con las campañas primaverales y ferias ocasionales, y los autores menos consolidados, dependientes en gran medida de la red de comercios que le dan visibilidad a sus obras, los que sufrirán las consecuencias económicas de la depresión con mayor crudeza. El ámbito de la cultura no es homogéneo, y en esta suerte de orgía cultural por la liberación de contenidos, el libre acceso a estos, de manera total o parcial, no representa lo mismo en una pequeña editorial que un gran grupo. Y la realidad es que la gran mayoría de las empresas editoriales que garantizan la innovación, la creatividad y la bibliodiversidad son iniciativas de autoempleo, o muy próximo a este. La disyuntiva para la supervivencia de la cultura no ha de ser si se produce o no la intervención del estado, sino cuál es la forma más adecuada para que se produzca esta, y como se aplica para que haya unos sistemas de retribución justos de los actores culturales $y$, sobre todo, para que puedan desarrollar una alternativa razonable al régimen de monopolio de las grandes plataformas de contenidos. ${ }^{6}$ Paul Valery denominaba como "profesiones delirantes", a las que se fundamentaban en la imaginación y carecían de una utilidad práctica inmediata. Aunque exagerado, el apelativo puede convertirse en un vaticinio certero para los que han hecho de la práctica cultural su vocación.

En segundo lugar, hay razones de carácter cultural. Todavía vivimos en una cultura en la que opera una suerte de "mitología de la presencia", como subraya Vitali-Rosati (2016), en la que la marca de la autenticidad está determinada por la inmediatez de lo físico. Una idea que ya había anticipado Benjamin (2017) cuando hablaba de una suerte de sacralización de los objetos, en tanto que son originales e inmediatos, para referirse a las obras de arte. Una presencialidad muy vinculada a los lugares en los que se desplegaba la cultura en general y la lectura en particular, dotando a sus espacios de un aura que participaba de las hierofanías de Mircea Eliade (2014). Y muchas de las invocaciones que se han hecho para la supervivencia de un ecosistema cultural amenazado y en trance de desaparición, beben de esta inspiración taumatúrgica.

La lectura como derecho era un bien generalizado entre las sociedades desarrolladas, sobre todo después de que las políticas de democratización cultural emprendidas a partir de la década de los años 50 del siglo XX propiciaran una extensión de la alfabetización en todo el mundo, y la creación de una red de bibliotecas públicas que alimentara las necesidades de la población lectora. Con el cierre de bibliotecas y de librerías, era la primera vez en la historia que los ciudadanos carecían de la oportunidad de ejercer ese derecho, por lo que las acciones de visibilización y promoción de las colecciones digitales públicas y las acciones emprendidas por autores, editores y plataformas de distribución, constituyeron una reacción lógica ante una necesidad perentoria de consumo de contenidos en un formato accesible desde el espacio doméstico. Aunque estas acciones de apertura puedan ser criticadas, como las que emprendió Internet Archive, no dejan de ser actuaciones extraordinarias para un momento extraordinario, en el que las normas consensuadas y asumidas por todos quedan en suspenso.

El acceso a los espacios públicos y privados de contenidos digitales desveló, para gran parte de la población, un universo nuevo en el que nutrirse para los tiempos de ocio dilatados, de encierro forzoso, como el provocado por las leyes de confinamiento. Es cierto que se podían considerar como meros reclamos los contenidos para descarga ofrecidos por algunos editores o autores, que representaban una proporción nimia en comparación con su fondo, que incluso podían ser percibidos como una forma de marketing, aunque de resultado incierto, pero el efecto reunido de todas estas acciones ha puesto en el escaparate otras formas de hacer y consumir cultura que podría persuadir en el futuro a una parte de la población afec-

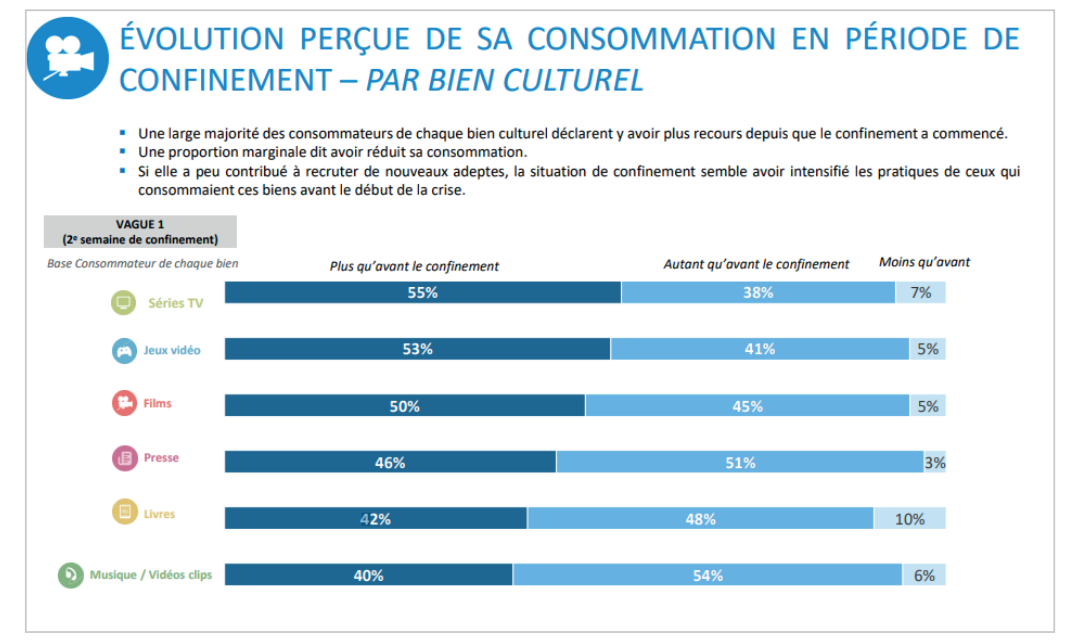

Figura 7. Percepción del consumo de bienes culturales. Fuente: Hadopi (2020) 
tada y que, sobre todo, actuará como recordatorio para futuras crisis. Aún no se han hecho investigaciones sobre los cambios de percepción de la población en torno a los distintos bienes culturales a raíz de la epidemia. Uno de los primeros fue el desarrollado en Francia por Hadopi, realizado en abril de 2020. Las respuestas son bastante elocuentes, pues de todas las actividades elaboradas habitualmente es precisamente la cultura, en sus diversas manifestaciones, la que destaca sobre el resto. $Y$ dentro del contexto de esta, todos los parámetros experimentan crecimientos

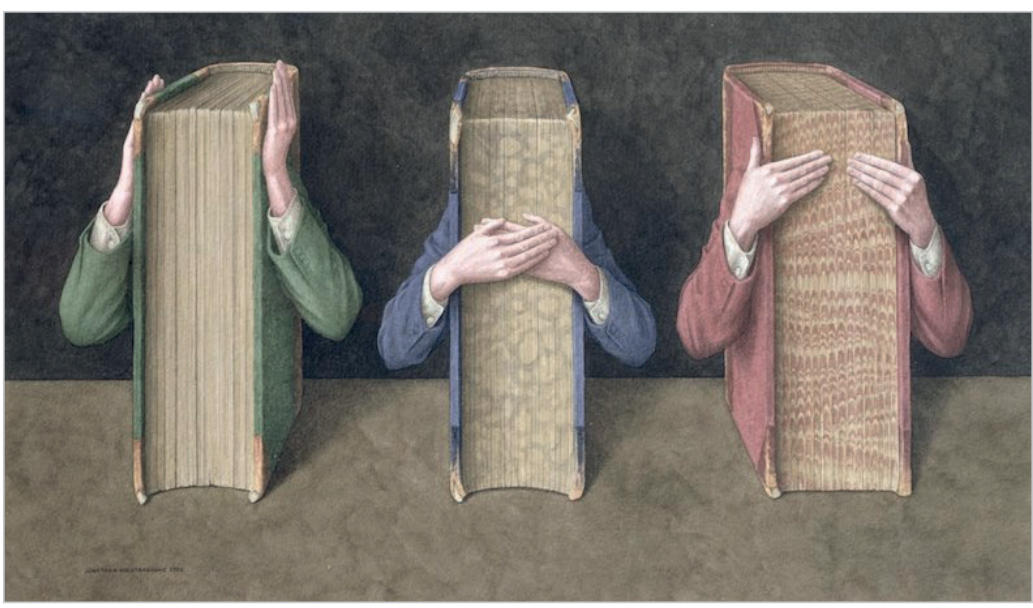

Figura 8. Pintura de Jonathan Wolstenholme de libros antropomorfizados. Fuente: https://cutt.ly/yyw1nTc importantes:

La vida la cambian sucesos impredecibles, no grandes revoluciones, y frente a esta suerte de mitología de la presencialidad se ha impuesto la idea de lo pulido, lo liso, lo impecable, que ya había definido Han (2015) como señas de identidad de nuestra época. Puede que sea una situación meramente coyuntural, provocada por esa suerte de delectatio morosa agustiniana, de profunda melancolía (Steiner, 2020) en la que se ha instalado una sociedad expectante e inquieta ante la incertidumbre que se vive, y en la que también se ha producido una suerte de confinamiento de los libros físicos limitados en sus prestaciones y funcionalidades más permeables.

El gesto de Rowling, la relajación de las políticas de protección de derechos sobre sus obras, aunque sea una actitud encomiable, es una más entre los miles de acciones que se han emprendido por parte de los diferentes actores de la cadena del libro. Sin embargo, su repercusión y visibilidad ha sido única, pues las noticias, comentarios y reflexiones que ha generado la sitúan de nuevo en la cúspide de la visibilidad mediática, necesaria para alimentar la voracidad insaciable del engranaje publicitario asociado a los bestsellers. Y es que una de las características de estas obras, como se ha visto, es que todo se aprovecha en su beneficio, incluso aquello que puede constituir un contrasentido con su naturaleza, como es la adopción de fórmulas que, en cierto modo, suponen una renuncia simbólica a la percepción estipulada por los derechos de uso. En una autora que tan celosa ha sido por la preservación de los mismos, emprendiendo todo tipo de acciones ante la sospecha de la quiebra de estos, que ha articulado todo un andamiaje empresarial en torno a sus creaciones y que controla de manera férrea la difusión de la mismas, una acción como esta cobra un significado paradójico, y en unas magnitudes impensables para cualquier otro autor.

En toda crisis siempre se enfrentan la racionalidad y el caos, se produce una especie de debate entre la tradición que tiende a mantenerse, y el elemento disruptivo que pugna por imponerse. En el ámbito de la cultura, la irrupción de internet y de las tecnologías digitales supusieron el mayor cambio experimentado en los últimos siglos, como han subrayado numerosos autores y estudiosos de la historia del libro. Curiosamente este ha sido el último formato en incorporarse a una ola de migraciones en la que las revistas, periódicos y obras de referencia, ya lo habían precedido. Amparado en un potente organigrama que había funcionado de manera fluida durante los dos últimos siglos, y cobijado en el componente emocional de un producto, el libro en papel, que sobrepasaba su dimensión cultural, había emprendido el cambio de una manera precavida y lenta, sin que los años transcurridos desde la aparición de los primeros dispositivos de lectura digital y las plataformas de contenidos en línea, hayan experimentado cambios significativos. De hecho, la edición digital supone un porcentaje muy pequeño de la edición total.

Pero una crisis como la de la Covid-19 ha puesto de manifiesto las ventajas de la separación, de la asepsia, de la manipulación virtual de los objetos de lectura, que nadie ha tocado ni poseído previamente, y que no tienen una entidad física contaminante. Como decía Muñoz Molina,

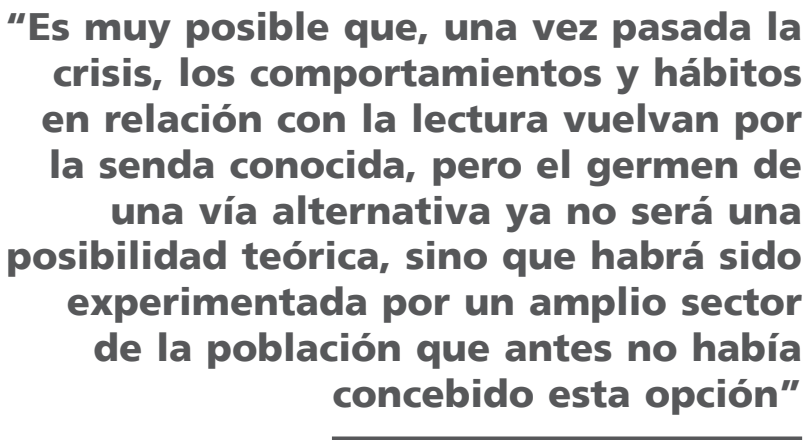

"Es muy posible que, una vez pasada la crisis, los comportamientos y hábitos en relación con la lectura vuelvan por senda conocida, pero el germen de xperimentada por un amplio sector concebido esta opción" 
“Las modestas variaciones sensoriales del tacto del papel — de libro, de periódico, de revista, de cuaderno, cada uno con cualidades distintas - o de las herramientas de trabajo —el lápiz, la pluma, el rotulador-quedan unificadas en la lisura de una pantalla táctil" (Muñoz-Molina, 2020).

Es muy posible que, una vez pasada la crisis, los comportamientos y hábitos en relación con la lectura vuelvan por la senda conocida, que los lectores regresen a su zona de confort en relación con sus prácticas culturales, pero el germen de una vía alternativa ya no será una posibilidad teórica, sino que habrá sido experimentada por un amplio sector de la población que antes no había concebido esta opción. Si bien podemos discutir los detalles de cifras (estas pueden ser muy conservadoras y cambiantes, ya que no tienen en cuenta el consumo no rastreado en plataformas como Amazon, Apple, Scribd, etc.), de lo que podemos estar seguros es de que el patrón está siendo replicado en todo el mundo donde los libros digitales estén disponibles. Decía Williams (2017) que, en los mitos, hay dos caminos hacia el desastre. Uno de ellos consistía en responder a una pregunta que no tenía respuesta. El otro era no ser capaz de responder a una pregunta que sí la tenía. Las respuestas desde al ámbito de la cultura a una situación extrema de confinamiento han puesto de manifiesto que había formas de participación no suficientemente explotadas, que han vivido soterradas bajo los prejuicios de la potencia simbólica de lo presencial en la cultura contemporánea. Ahora más que nunca se ha podido comprobar que, como subraya Jarrige (2016), la oposición entre las dos figuras antitéticas del tecnófilo y el tecnófobo merece ser cuestionada porque es una construcción sociocultural deudora de posiciones en las que la tradición se ha venido imponiendo por inercia, más que por necesidad. De manera que una situación crítica puede haber desencadenado el nacimiento de otras formas de percepción y acceso al conocimiento, no solo recreativo, sino también formativo. El tiempo dirá cuáles serán los efectos reales que toda esta transformación, tan inesperada como intensa en el tiempo, tendrá sobre los hábitos de consumo de la población, pero la semilla del cambio ya se ha sembrado. Está en la naturaleza de las ideas que nazcan como molestas herejías y mueran como aburridas ortodoxias, señalaba Bauman (2012). Lo digital va recorriendo ese camino, acelerado por acontecimientos como el que sufrimos. Ahora lo importante, como diría León Felipe, "no es llegar solo ni pronto, sino llegar con todos y a tiempo".

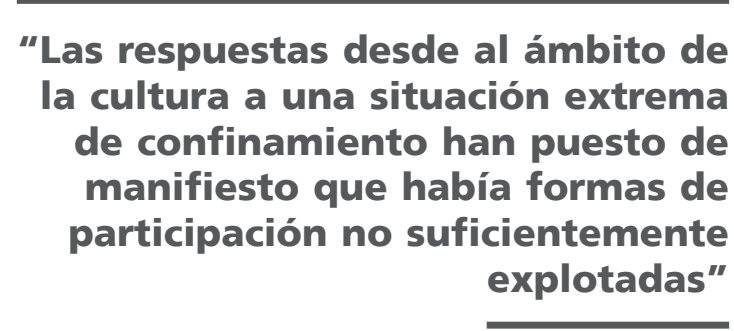

\section{Notas}

1. Entre las editoriales y plataformas académicas, Cambridge University Press, Cengage, Macmillan Learning, McGraw-Hill. W. W. Norton, Oxford University Press, Pearson, SAGE Publishing, Scholastic, Wiley, Bookshare, RedShelf, VitalSource, Emerald Group, Springer Publishing Company, Taylor \& Francis, Wolters Kluwer, JSTOR, ProQuest, etc., han creado materiales de aprendizaje y herramientas para facilitar la enseñanza a distancia, al tiempo que facilitan el acceso a gran parte de sus contenidos. Por su parte, Bloomsbury, Hachette Book Group, HarperCollins Publishers, Penguin Random House, Simon \& Schuster, Independent Publishers Group (IPG), han dejado algunas de sus obras en libre acceso para la lectura online.

2. Tiqqun es el nombre de una publicación francesa sobre filosofía, fundada en 1999. Tiqqun es también un concepto filosófico, emanado de los textos publicados en la revista, que designa, no tanto un autor colectivo, como una filosofía de carácter colaborativo y compartida.

3. El informe se interrumpió en el año 2012, y no se reanuda hasta el año 2018, en el que se publican los datos relativos a 2017.

4. Según los datos aportados por Libranda, una de las principales distribuidoras de libros digitales en España, la venta de libros electrónicos ha crecido un $50 \%$ por término medio desde que comenzó el confinamiento. Se trata de un incremento que afecta tanto a los grandes grupos como Planeta o Penguin Random House, como a editoriales más pequeñas con oferta digital. Este incremento afecta también a los tiempos de lectura. Un estudio desarrollado por Nubico (plataforma de suscripción del Grupo Planeta) entre sus miembros muestra cómo, además de un fuerte crecimiento en las altas de nuevos suscriptores, el tiempo medio dedicado a la lectura ha aumentado en un $50 \%$. Comscore, una de las empresas más significativas en la medición de audiencias y difusión de mercado, realizó un estudio sobre los efectos del coronavirus en el comportamiento de consumo. Une de los aspectos estudiados es el relativo a la venta de libros. Según el análisis en las dos últimas semanas de marzo se habría incrementado considerablemente la compra de libros físicos a través de las tiendas online, pero sobre todo se habría producido un fuerte aumento del consumo de libros electrónicos y audiolibros, de en torno al 30\% (Gevers, 2020). Algo constatado por Rankuten-Kobo, que experimentó una acentuación del 200 al 300\% en la lectura media a través de su plataforma, tanto en Francia como en Italia y España, en la última semana de marzo (Gary, 2020) 
5. Según el Ministerio de Cultura y Deporte las altas en el servicio de préstamo de libros electrónicos de bibliotecas públicas crecieron un $129,82 \%$, dándose de alta 18.323 nuevos usuarios hasta alcanzar un total de 32.431 durante el mes de marzo. También se incrementó el número de préstamos durante ese mes, aumentando 24.827 respecto al mes de febrero. Por otra parte, la página web de Ebiblio recibió casi un millón de visitas durante ese período. En Cataluña, el catálogo digital de las bibliotecas públicas \#eBiblioCat aumentó un $500 \%$ el número de visitas en los dos primeros días de confinamiento y el préstamo de libros electrónicos creció un $150 \%$ durante los días 13 y 14 de marzo. En Castilla y León durante el mes de marzo de 2020 aumentó en un $120 \%$ el número de préstamos y un $300 \%$ el número de altas a eBiblio. Si se comparan los meses de marzo de 2019 y 2020, el aumento sería de un $120 \%$ en el número de préstamos, de un $300 \%$ en el número de altas, y de un $145 \%$ en el número de usuarios activos, acrecentando también en un $\mathbf{2 8 0 \%}$ las visitas a la plataforma. En otros países el fenómeno ha sido el mismo:

- en Canadá, por ejemplo, Quebec puso en marcha Pretnumerique.ca en el año 2012, con 850.000 títulos. En el mes de marzo de 2019, se hicieron 169.726 préstamos desde la plataforma, en el mismo mes de 2020, 265.021, casi 100.000 préstamos más;

- en el Reino Unido la biblioteca de Hampshire County Council incrementó en un $770 \%$ los nuevos usuarios digitales, la de Cornwall en un $630 \%$, o la de Hertfordshire en un $332 \%$.

Según las estadísticas aportadas por Overdrive se prestaron 10,1 millones de libros electrónicos desde las bibliotecas públicas en todo el mundo, vía Libby, en una semana.

6. En el último informe de Libranda sobre el libro digital en España (2020) se puede comprobar el monopolio que sobre el mercado del libro digital detentan las plataformas de venta y distribución internacionales (Amazon, Google, Apple, principalmente). Mientras que esas han alcanzado una cuota de mercado del 78,9\%, en 2019, las librerías y plataformas online independientes solo llegan al $11 \%$.

\section{Referencias}

AAP (2019). Statement on flawed theory of "Controlled Digital Lending". Association of American Publishers. https://publishers.org/news/statement-on-flawed-theory-of-controlled-digital-lending

Almjawel, Aljoharah; Bayoumi, Sahar; Alshehri, Dalal; Alzahrani, Soroor; Alotaibi, Munirah (2019). "Sentiment analysis and visualization of Amazon Books' reviews". In: 2nd International Conference on Computer Applications and Information Security, ICCAIS'2019, art. no. 876958.

Anderson, Porter (2019). "Authors guild and society of authors allege copyright infringement by the Internet Archive". Publishing perspectives, January 18.

https://publishingperspectives.com/2019/01/copyright-battle-internet-archives-open-library-authors-guild-societyof-authors

Bauman, Zygmunt (2002). La cultura como praxis. Barcelona: Paidos. ISBN: 9788449311840

Benjamin, Walter (2017). La obra de arte en la época de la reproducción mecánica. Buenos Aires: La Marca Editora. ISBN: 9788493837525

Bourdieu, Pierre (2018). Las reglas del arte: génesis y estructura del campo literario. Barcelona: Anagrama. ISBN: 9788433913975

Carrión, Jorge (2019). Contra Amazon. Barcelona: Galaxia Gutenberg.

Cordón-García, José-Antonio; Gómez-Díaz, Raquel (coords.) (2019). Lectura, sociedad y redes: colaboración, visibilidad y recomendación en el sistema del libro. Madrid: Marcial Pons. ISBN: 9788491235774

Eliade, Mircea (2014). Lo sagrado y lo profano. Barcelona: Paidos. ISBN: 9788408180241

Ertzscheid, Olivier (2017). L'appétit des géants: pouvoir des algorithmes, ambitions des plateformes. Paris, C\&F editions. ISBN: 9782915825701

Gary, Nicolas (2020). "Lecture numérique: la France connait une embellie". Actualitté, 31 marzo. https://www.actualitte.com/article/lecture-numerique/lecture-numerique-la-france-connait-une-embellie/100018

Gevers, Alex (2020). "Coronavirus pandemic and online behavioural shifts". Comscore, 30 marzo. https://www.comscore.com/lat/Insights/Blog/Coronavirus-pandemic-and-online-behavioural-shifts-March-30-update

FGEE (2001-2020). Hábitos de Lectura y Compra de Libros 2000-2019. Madrid, Federación de Gremios de Editores de España (FGEE).

Hadopi (2020). Consommation de biens culturels dématérialisés en situation de confinement. Avril 2020.

https://www.hadopi.fr/sites/default/files/sites/default/files/ckeditor_files/Barometre_Hadopi_Consommation_ dematerialisee_en_situation_de_confinement_2020_04_07.pdf

Han, Byung-Chul (2015). La salvación de lo bello. Barcelona: Herder.

Hasbrouck, Edward (2020). "What is the Internet Archive doing with our books?". National Writers Union, 16 abril. https://nwu.org/what-is-the-internet-archive-doing-with-our-books 
Hou, Lei; Liu, Kecheng; Liu, Jianguo (2018). "Navigated random walks on Amazon Book recommendation network". Studies in computational intelligence, n. 689, pp. 935-945.

https://doi.org/10.1007/978-3-319-72150-7_75

Jarrige, François (2016). Technocritiques: du refus des machines à la contestation des technosciences. Paris: La Decouberte. ISBN: 9782707178237

Libranda (2020). Informe anual del libro digital 2019.

https://libranda.com/wp-content/uploads/2020/04/Informe-Anual-del-Libro-Digital-2019.pdf

Maity, Suman-Kalyan; Panigrahi, Abhishek; Mukherjee, Animesh (2017). "Book reading behavior on goodreads can predict the Amazon best sellers". In: Proceedings of the 2017 IEEEIACM International Conference on Advances in Social Networks Analysis and Mining, ASONAM 2017, pp. 451-454.

https://doi.org/10.1145/3110025.3110138

Muñoz-Molina, Antonio (2020). "Trabajos manuales". El país, Babelia, 22 abril. https://elpais.com/cultura/2020/04/15/babelia/1586950776_642455.html

Newhoff, David (2020). "Internet Archive uses pandemic to justify looting". The Illusion of More: dissecting the thigital utopia, 29 March.

https://illusionofmore.com/internet-archive-uses-pandemic-to-justify-looting

Raffaelli, Ryan L. (2020). Reinventing retail: The novel resurgence of independent bookstores. Harvard Business School. Working Paper 20-068.

https://www.hbs.edu/faculty/Publication\%20Files/20-068_c19963e7-506c-479a-beb4-bb339cd293ee.pdf

Reimers, Imke; Waldfogel, Joel (2017). "Throwing the books at them: Amazon's puzzling long run pricing strategy". Southern economic journal, v. 83, n, 4, pp. 869-885.

https://doi.org/10.1002/soej.12205

Ruiz, Bernat (2020). "Penguin Random House, o la mano invisible de la distribución (en España)". Verba volant, scripta manent: el blog de Bernat Ruiz, 9 abril.

http://www.bernat-ruiz.com/2020/04/09/penguin-random-house-o-la-mano-invisible-de-la-distribucion-en-espana

Shephard, Alex (2020). "Is This the End of the Indie Bookstore?: How booksellers are coping with the coronavirus crisis-and what comes next". The new republic, 16 abril.

https://newrepublic.com/article/157315/end-indie-bookstore

Steiner, George (2020). Diez (posibles) razones para la tristeza del pensamiento. Barcelona: Siruela. ISBN: 978 8498410334

Strauss, Victoria (2020). "Copyright violation redux: The Internet Archive's National Emergency Library". Writer beware, 31 marzo.

https://accrispin.blogspot.com/2020/03/copyright-violation-redux-internet.htm/

Strujan, K. S.; Nikhil, S. S.; Raghav-Rao, H.; Karthik, K.; Harish, B. S.; Keerthi-Kumar, H. M. (2018). “Classification of Amazon book reviews based on sentiment analysis". Advances in intelligent systems and computing, $\mathbf{v}$. 672, pp. 401-411.

https://doi.org/10.1007/978-981-10-7512-4_40

Vitali-Rosati, Marcello (2016). "Mediateté de la présence et multiplicité ontologique". Culture numérique: pour una philosophie du numérique, 4 marzo.

https://blog.sens-public.org/marcellovitalirosati/mediatete-de-la-presence-et-multiplicite-ontologique

Williams, Joy (2017). Cuentos escogidos. Barcelona: Seix Barral.

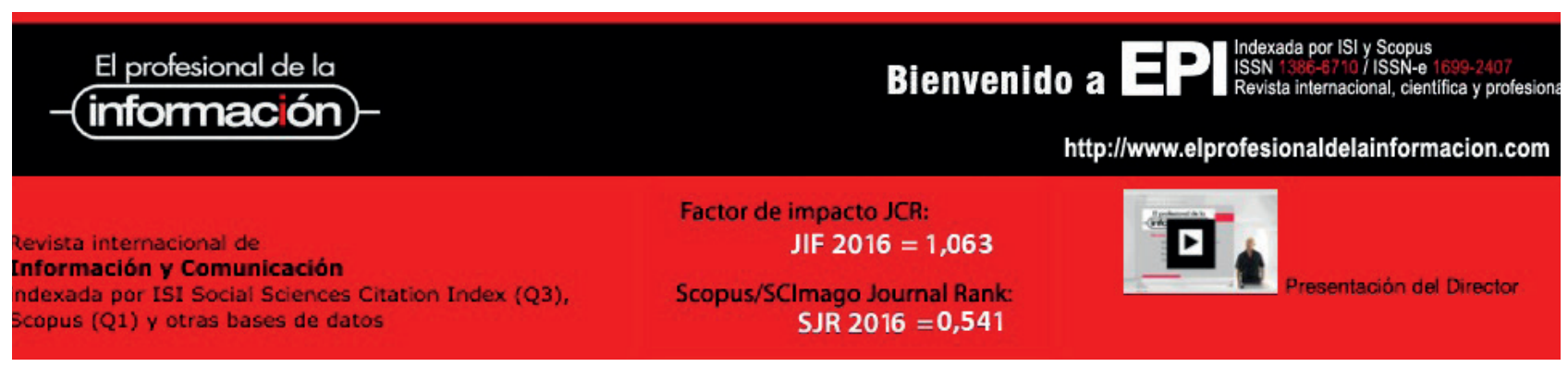

